\title{
MODELISATION OF THE COAL PULVERISE COMBUSTION
}

\author{
SAADAOUI M.*, MAHJOUB SAID N.*, MHIRI H.*, LE PALEC G.**, BOURNOT Ph.** \\ * Unité de thermique et environnement, Ecole Nationale d'Ingénieurs de Monastir, route de \\ Ouardanine 5020 MONASTIR, Tunisie \\ ** Equipe IMFT, Institut de Mécanique de Marseille, UNIMECA, 60 rue Juliot - Curie, \\ Technopôle de Château- Gombert, 13453 MARSEILlE Cedex 13, France,
}

The development of the clean coal techniques passes initially by the setting in conformity of the power stations with pulverized coal, where the fuel is pulverized in very fine dust in the crushers to facilitate combustion, is mixed with heated air and finally injected into the combustion chamber of the vapor generator. To decrease the emission in the atmosphere of polluting gases, one can add installations of denitrification and/or desulphurization. These processes act either on the level of combustion, or by a treatment of the fume.

The objective of this work is to lead and control combustion with the coal pulverized while knowing to observe the parameters of combustion, to establish a diagnosis, to bring the corrective actions with the permanent concern to optimize the output of combustion and to reduce the emissions of gaseous pollutants.

This work treats the numerical modeling of the combustion of a pulverized jet of solid combustion [1]. Our simulation is based on the resolution of the average equations of Navier-stokes coupled with the conservation equation of the enthalpy and the conservation of the species. For the closing of the equations of turbulence we chose the model $k-\varepsilon$ Standard [2]. The modelling of the reactions of devolatilisation and combustion is made according to the model of assessment of density of probability (PDF) [3]. We used the method of the volumes finished for the numerical resolution of the partial derivative equations.

\section{Bibliography}

[1] F. C. Lockwood et A. P. Salooja (1983), The prediction of some pulverized bituminous coal in a furnace, Combustion and flame, vol. 56, pp 23-32.

[2]B. E. Launder and D. B. Spalding, Lecture sin Mathematical Models of Turbulence, Academic Press, London, England, 1972.

[3] Borghi R. Destriau M., La combustion et les flammes; technip 1995, pp 37.3. 